\title{
Excitation-Contraction Coupling in Developing Mammalian Myocardium: Evidence from Voltage Clamp Studies
}

\author{
THOMAS KLITZNER AND WILLIAM F. FRIEDMAN
}

Division of Cardiology, Department of Pediatrics, UCLA School of Medicine, UCLA Medical Center Los Angeles, California 90024

\begin{abstract}
The single sucrose gap voltage clamp technique was used to study excitation-contraction coupling processes in right ventricular papillary muscles from New Zealand White rabbits at various stages of development. In response to voltage clamp controlled depolarizations, muscles from newborn rabbits were found to exhibit a monotonically increasing tension response reaching a steady state level that was maintained for the duration of depolarization. In contrast, more mature myocardium responded to similar depolarizations by developing an early peak of tension before relaxing to a steady state level Measurement of the ratio of early peak or phasic tension to steady state or tonic tension revealed a statistically significant increase in the phasic tension component with maturation. In addition, $\mathrm{Ca}^{2+}$ loading of immature myocytes via a conditioning voltage clamp step resulted in enhancement of phasic tension in subsequent test depolarizations. Finally, the voltage dependence of tonic tension was found to be the same in all age groups. In contrast, the voltage dependence of phasic tension, seen only in the more mature myocardium, differed from that of tonic tension. The results of this investigation suggest that tension development in the immature myocardium is supported largely by the influx of $\mathrm{Ca}^{2+}$ across the sarcolemma. As the myocardium matures, intracellular $\mathrm{Ca}^{2+}$ uptake and rerelease by the sarcoplasmic reticulum plays an increasingly important role in tension development. A developmental schema is presented to account for the observed maturational changes in excitation-contraction coupling. (Pediatr Res 23: 428-432, 1988)
\end{abstract}

\section{Abbreviations}

$P / T$, ratio of phasic to tonic

Myocardial contraction results from an increase in free myoplasmic calcium brought about by the combination of an influx of extracellular $\mathrm{Ca}^{2+}$ and the release of $\mathrm{Ca}^{2+}$ from internal stores (1-3). In the adult myocardium it has been estimated that the percentage of activator $\mathrm{Ca}^{2+}$ which is made available to the myofilaments via transsarcolemmal $\mathrm{Ca}^{2+}$ influx varies from 30 to $70 \%$ with the remainder supplied by release of $\mathrm{Ca}^{2+}$ from the sarcoplasmic reticulum (2). In addition, it has been shown that influx of $\mathrm{Ca}^{2+}$ from the extracellular space in adult myocardium

Received October 9, 1987; accepted December 17, 1987.

Reprints and correspondence Dr. Thomas Klitzner, Department of Pediatrics, B2-411 MDCC, UCLA School of Medicine, Los Angeles, CA 90024.

Supported in part by NIH Grant K08 HL01347 and R01 HL35783 and the American Heart Association, Greater Los Angeles Affiliate Grant 829 G1. may be responsible, in part, for the replenishment of internal $\mathrm{Ca}^{2+}$ stores (2).

Recently, evidence has become available to suggest that immature myocardium relies largely on transsarcolemmal $\mathrm{Ca}^{2+}$ influx to provide the activator $\mathrm{Ca}^{2+}$ required to support contraction (4-7). In this regard the immature myocyte does not possess the well-developed t-tubular system and sarcoplasmic reticulum of the adult (7-11); myofibrils are less well organized and tend to lie closer to the sarcolemma than in the adult $(9,10)$; and mitochondria differ in configuration and occupy less total volume than in mature myocardium (8).

The single sucrose gap voltage clamp technique provides the opportunity to study intracellular $\mathrm{Ca}^{2+}$ regulation in a quantitative fashion. Using this technique it is possible to control the membrane potential while simultaneously measuring developed tension in cardiac tissue preparations (12). The membrane potential, rather than following the course of a normal action potential, may be rapidly increased to a predetermined level for a variable period of time. Thus, the level and duration of depolarization may be independently controlled, and the voltage and time dependence of tension generation studied. Accordingly, the purpose of the present investigation was to use the single-sucrose gap voltage clamp technique to evaluate the relative contribution of transsarcolemmal $\mathrm{Ca}^{2+}$ influx and release of $\mathrm{Ca}^{2+}$ from intracellular stores in the generation of tension in mammalian myocardium as it matures from newborn to adult.

\section{METHODS}

Preparation. Right ventricular papillary muscles $0.3-0.7 \mathrm{~mm}$ in diameter were dissected from New Zealand White rabbits from three age groups: newborns (0-10 days), juveniles (18-29 days), and adults. Muscles were placed in a three compartment, single sucrose gap chamber (Fig. 1). The tendinous end of the papillary muscle was fastened with fine suture to an isometric tension transducer in the physiologic chamber and the cut end was pulled through adjustable holes in the rubber membranes separating the larger outer compartments from the central chamber. The cut end was left loose in the outer chamber containing $\mathrm{KCl}$-Tyrodes solution $\left(\mathrm{KCl} 128 \mathrm{M}: \mathrm{KHCO}_{3} 24 \mathrm{M}\right)$. Typically $0.4-1.0 \mathrm{~mm}$ of the tendinous end of the muscle protruded into the physiologic compartment through which oxygenated tyrodes solution $\left(\mathrm{NaCl} 118 \mathrm{M} ; \mathrm{CaCl}_{2} 1.0 \mathrm{M}\right.$; glucose $6 \mathrm{M}: \mathrm{MgCl}_{2} 1.0 \mathrm{M}$; $\mathrm{KCl} 4.0 \mathrm{M} ; \mathrm{NaHCO}_{3} 24 \mathrm{M} ; \mathrm{NaH}_{2} \mathrm{PO}_{4} 0.435 \mathrm{M}$ ) flowed at a constant rate $(2-3 \mathrm{ml} / \mathrm{min})$. Oxygenated, isosmotic sucrose (sucrose $280 \mathrm{M}$-high purity, Grade I, Sigma Chemical Company, St. Louis, MO) flowed at a rapid rate $(2-6 \mathrm{ml} / \mathrm{min})$ through the middle compartment. Preparations were stimulated at six shocks/min by passing $5 \mathrm{~ms}$ current pulses to raise the membrane potential to twice threshold and were allowed to stabilize in the experimental chamber for $45 \mathrm{~min}$ before the start of an experi- 


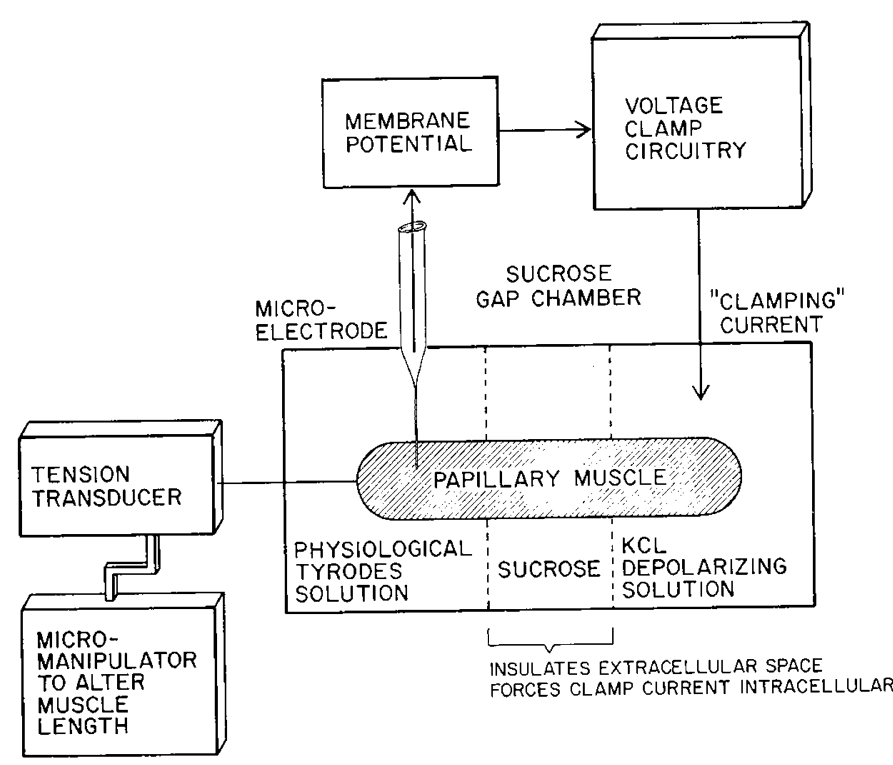

Fig. 1. Experimental chamber-a schematic representation of the single sucrose gap voltage clamp chamber is shown. A papillary muscle is attached by fine suture to the tension transducer and pulled through adjustable holes in the latex rubber membranes (dotted lines) separating the two outer chambers from the middle chamber. The length of the muscle in the physiologic chamber is adjusted using the micromanipulator. A glass microelectrode impales a cell in the center of the physiologic portion of the preparation and measures the intracellular membrane potential. This potential is fed through the voltage clamp circuitry that supplies the "clamping" current into the $\mathrm{KCl}$ chamber to hold the physiologic portion of the preparation at a predetermined clamp potential. The clamping current is forced by the insulating properties of the extracellular sucrose solution to flow intracellularly through the preparation in the sucrose "gap" and uniformly depolarize the physiologic portion of the preparation.

ment. The control tyrodes solution was equilibrated with $95 \%$ $\mathrm{O}_{2}$ and $5 \% \mathrm{CO}_{2}$, and all experiments were conducted at $20-23^{\circ}$ C.

Stimulating or clamping current was applied to the preparation across the sucrose gap employing $\mathrm{Ag} / \mathrm{AgCl}$ electrodes close to the muscle. The potential of the surface of the muscle in the physiologic compartment was held to ground potential by a separate circuit (virtual ground). Transmembrane potential was measured relative to virtual ground with conventional $3 \mathrm{M} \mathrm{KCl}$ filled glass microelectrodes connected to the input of a solid state negative capacitance preamplifier (World Precision Instruments). In voltage clamp experiments the output of the preamplifier was fed into the voltage clamp circuitry which supplied the necessary "clamping" current to the $\mathrm{KCl}$ pool. The insulating properties of the extracellular sucrose caused this current to flow intracellularly through the muscle in the sucrose compartment to uniformly depolarize the muscle in the physiologic bath

Measurement of tension. Tension was measured using a highly stable, temperature insensitive, capacitive-coupled transducer (Dynagauge). A micromanipulator was used to adjust the length of the segment of muscle in the physiologic compartment to bring it close to the apex of its length tension relation. The segment of muscle bathed in sucrose was kept slack to prevent it from contributing to the measured tension. This arrangement allowed for some internal shortening of the myofilaments in the portion of muscle in the physiologic bath and, hence, the measured tension was very nearly, but not perfectly, isometric.

Measurement of current. The "clamping" current, representing the transmembrane current (plus small leakage currents), was measured by the virtual ground circuit. Current was recorded during all voltage clamp experiments as the current record provided a check on the homogeneity of voltage clamp control.
Approximately $40 \%$ of all papillary muscles met the criteria for good voltage clamp control. The validity and limitations of the single sucrose gap voltage clamp technique have been discussed previously $(12,13)$.

Statistical methods. Results within age groups were analyzed using paired $t$ tests allowing each preparation to serve as its own control. Comparisons between age groups were made using the Student's $t$ test for pairwise comparisons or analysis of variance to analyze changes across all three age groups.

Because of the variable size and taper of the physiologic portion of different papillary muscles, accurate normalization of tension measurements by weight or cross-sectional area was not possible. Therefore, statistical analysis was performed only on nondimensional ratios.

\section{RESULTS}

Comparison of the immature and mature tension response. Mature mammalian ventricular muscle responds to long, voltage clamp controlled depolarizations with a biphasic tension response $(2,14,15)$. As seen in the bottom right panel of Figure 2 , when a $2 \mathrm{~s}$ voltage clamp step to the plateau level was imposed on an adult right ventricular papillary muscle, the muscle first developed an early peak tension (phasic tension), which then relaxed to a lower steady state level (tonic tension). By comparison, the response of newborn myocardium to a long voltage

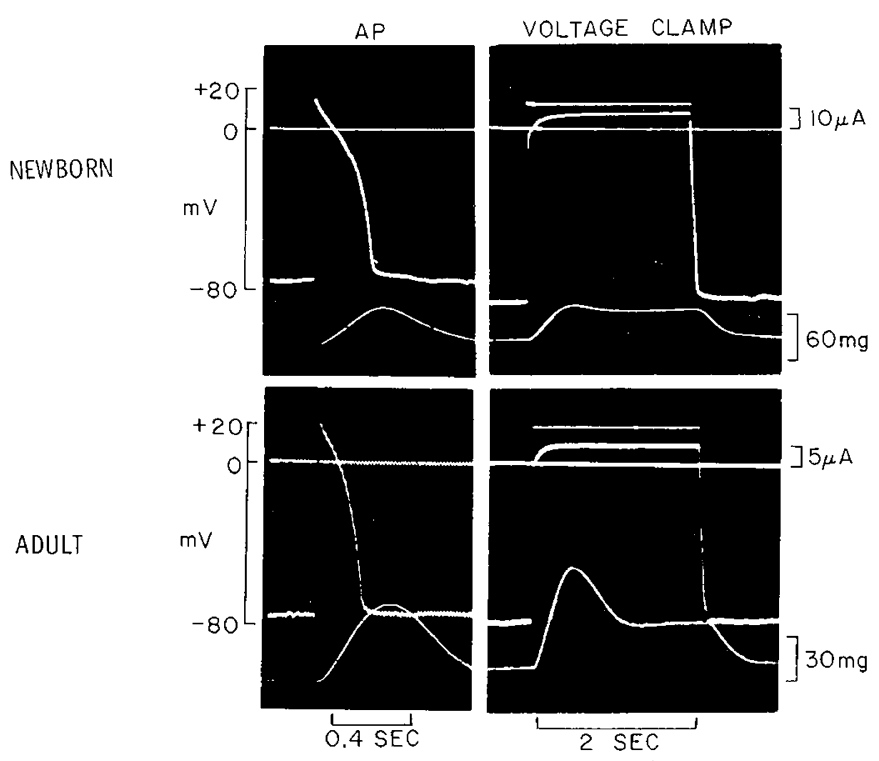

Fig. 2. The upper and lower left-hand panels show an action potential and the accompanying tension response in a newborn (top) and adult (bottom) papillary muscle. Note that despite the apparent similarity of the tension response in the two age groups, the tension response in the newborn begins to relax immediately on repolarization of the action potential, whereas in the adult, the peak of tension occurs after repolarization is complete. The response to a $2 \mathrm{~s}$ voltage clamp step to $+10 \mathrm{mV}$ is shown for the two age groups in the left-hand panels. Three traces are displayed in each panel. Membrane potential is taken from rest $(-80$ $\mathrm{mV}$ ) to $+10 \mathrm{mV}$ by the voltage clamp circuitry. After a 2 s depolarization, the membrane potential is allowed to return to rest. The current trace (top of each panel) represents the net membrane current that flows during the clamp step. The line at $0 \mathrm{mV}$ represents zero current flow (inward current is displayed as negative). The tension response is shown at the bottom of each panel. Note that the adult responds to the clamp step with both early peak (phasic) and steady state (tonic) tension whereas the newborn develops only tonic tension. The magnitude of tonic tension in the newborn is equal to that of the twitch tension while in the adult, tonic tension represents slightly more than half the twitch height. Also of interest is the fact, that in both age groups, the tonic tension component begins to relax immediately on repolarization. 
clamp step was not biphasic; no early peak of tension was seen (Fig. 2, top right panel). Rather, tension increased monotonically to a final steady state level where it was maintained for the duration of the clamp step. This distinction between the mature and immature tension response was not evident in the twitch response accompanying an action potential which appeared very similar in the neonate and in the adult (upper and lower lefthand panels of Fig. 2). The only difference was that the peak of tension in the adult followed the rapid repolarization phase of the action potential, while in the newborn, tension began to relax immediately on repolarization. Comparison of the amplitude of the twitch and clamp-induced tension revealed that twitch tension and steady state tension were of the same approximate magnitude in the newborn. In contrast, in the adult, both twitch tension and phasic tension were larger than steady state tension.

Changes in the identified tension components with development. To delineate the changes that take place in the relative magnitude of phasic and tonic tension with development, long voltage clamp steps to the plateau level were imposed on papillary muscles from newborn, juvenile, and adult rabbits. In Figure 3 the original records of a typical experiment on a juvenile rabbit papillary muscle were combined with the records from the newborn and adult preparations shown in Figure 2. Note that phasic tension was absent in the newborn, present but small in the juvenile, and largest in the adult. In order to quantify the change in the relative contributions of these two tension components with age, a ratio of phasic to tonic tension was measured during a clamp step to the plateau level. This $\mathrm{P} / \mathrm{T}$ ratio was measured in six newborn, five juvenile, and five adult rabbits. The newborn group showed little or no early peak tension $(\mathrm{P} / \mathrm{T}=0.9 \pm 0.3$; mean $\pm \mathrm{SD}$ ); whereas phasic tension began to develop in the juvenile group $(\mathrm{P} / \mathrm{T}=1.4 \pm 0.3)$ and was maximal in the adults $(\mathrm{P} / \mathrm{T}=2.6 \pm 0.6)$. This increase in the $\mathrm{P} / \mathrm{T}$ ratio with age is statistically significant $(p<0.05)$.

Effects of calcium loading. Experiments on adult mammalian myocardium suggest that the phasic component of tension results from release of a bolus of $\mathrm{Ca}^{2+}$ from the sarcoplasmic reticulum (2). Thus, a conditioning clamp step might load the sarcoplasmic reticulum with $\mathrm{Ca}^{2+}$ and result in an increase in phasic tension. A typical experiment in a newborn rabbit is shown in Figure 4. A train of action potentials was interrupted by two consecutive clamp steps near the plateau potential. The conditioning clamp step (left panel) was accompanied by a tension record that showed little or no phasic tension. However, the prolonged tension response that accompanied this conditioning clamp step indicates an increased intracellular $\mathrm{Ca}^{2+}$ load. The test clamp step, which immediately followed the $\mathrm{Ca}^{2+}$-loading conditioning clamp step, was accompanied by an increase in the phasic
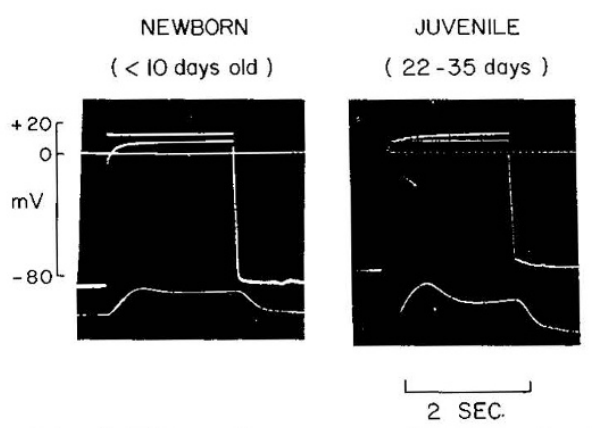

\section{ADULT}

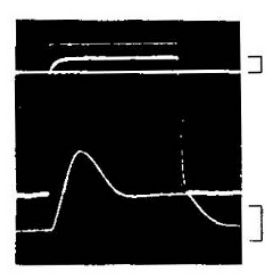

Fig. 3. Voltage clamp steps to the plateau level are shown for papillary muscles from newborn, juvenile, and adult rabbits along with the accompanying current and tension records. Note that the phasic tension is virtually absent in the newborn, present but small in the juvenile, and quite prominent in the adult. Tension bars to the right of the figure represent $60 \mathrm{mg}$ for the newborn and $30 \mathrm{mg}$ for the juvenile and adult. Zero current is represented by the bottom of the current bar to the right of the figure representing $10 \mu \mathrm{A}$ for all current traces.

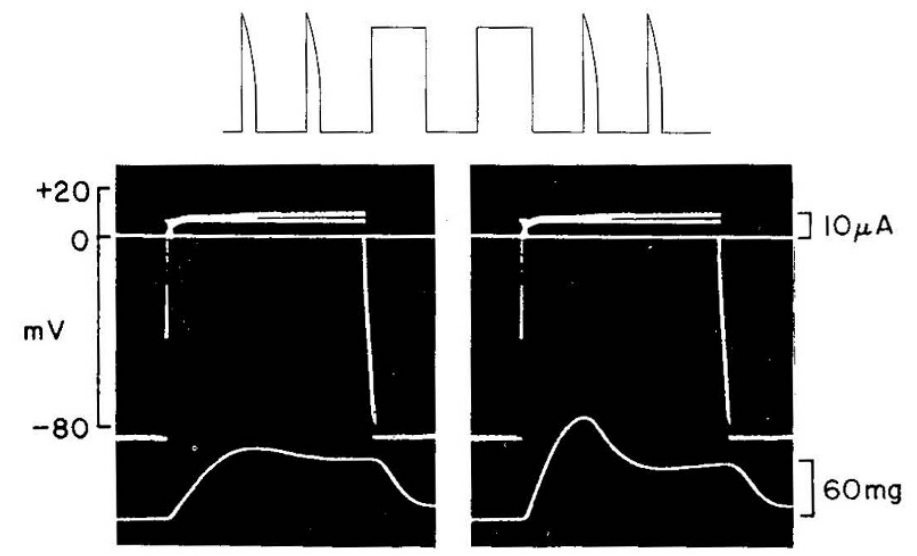

Fig. 4. The effect of a conditioning clamp step in the newborn-a train of stimulated action potentials is interrupted by two consecutive clamp steps to the plateau potential in a papillary muscle from a newborn rabbit. In response to the first depolarization (left panel) virtually no phasic tension develops. The prolonged tension response to this first voltage clamp step, however, indicates an increase intracellular $\mathrm{Ca}^{2+}$ load. This increase in intracellular $\mathrm{Ca}^{2+}$ is reflected in the subsequent clamp step by the appearance of a phasic component of tension (right panel). The phasic tension seen in response to the second clamp step is thought to result from the release of $\mathrm{Ca}^{2+}$ from functionally immature sarcoplasmic reticulum loaded with $\mathrm{Ca}^{2+}$ during the, conditioning clamp step.

component of tension (compare right and left panels). Table 1 shows the results of this type of experimental protocol for five newborn and five juvenile rabbit papillary muscles. In both age groups the $\mathrm{Ca}^{2+}$-loading conditioning clamp pulse significantly increased the phasic component of tension.

The voltage dependence of the identified components of tension. The voltage dependence of tension generation may be studied using the voltage clamp technique by repeating clamp steps, such as those shown in Figure 2, and varying the degree of depolarization by altering the clamp potential. Measurement of phasic and tonic tension at each clamp potential allows construction of a graphical tension-voltage relation for each component of tension (Fig. 5). The top panel of Figure 5 shows the tension-voltage relation for the tonic component of tension in a typical newborn papillary muscle. The voltage threshold for the development of tonic tension was between -50 and $-60 \mathrm{mV}$. Above this threshold, tonic tension was a monotonically increasing function of membrane potential up to the highest potential tested. The lower graph of Figure 5 shows a typical tension-voltage relation for both the phasic and tonic tension of the adult rabbit papillary muscle. Of note is the fact that tonic tension showed a similar voltage dependence in the adult as in the newborn. Thus, tonic tension began to develop at -60 to $-50 \mathrm{mV}$ and had a monotonically increasing dependence on voltage up to the highest potential tested. However, in contrast to tonic tension, phasic tension increased with increasing membrane potential from -60 to $0 \mathrm{mV}$ and then declined with increasing clamp amplitude.

\section{DISCUSSION}

Our experiments disclosed a fundamental difference between newborn and adult myocardium in response to voltage clamp steps. Neonatal myocardium developed no significant phasic tension in contrast to heart muscle from both juvenile and adult rabbits. In addition, the ratio of phasic to tonic tension increased with age. $\mathrm{Ca}^{2+}$-loading of the newborn or juvenile myocardial cell via a conditioning clamp step increased the magnitude of phasic tension. Muscles from all age groups displayed tonic tension that was maintained for the duration of long $(2 \mathrm{~s})$ voltage clamp steps and relaxed immediately on repolarization. At all ages the relationship was similar between membrane voltage and final tonic tension. However, the voltage dependence of phasic 
Table 1. Effect of $\mathrm{Ca}^{2+}$ loading on ratio of phasic to tonic tension in newborn and juvenile myocardium (mean $\pm S D$ )

\begin{tabular}{ccc}
\hline P/T ratio & Control & Test \\
\hline Newborn $(n=5)$ & $0.9 \pm 0.3$ & $1.6 \pm 0.3^{*}$ \\
Juvenile $(n=5)$ & $1.4 \pm 0.3$ & $2.5 \pm 0.8^{*}$ \\
\hline
\end{tabular}

${ }^{*}$ Differences significant at the $p<0.01$ level.

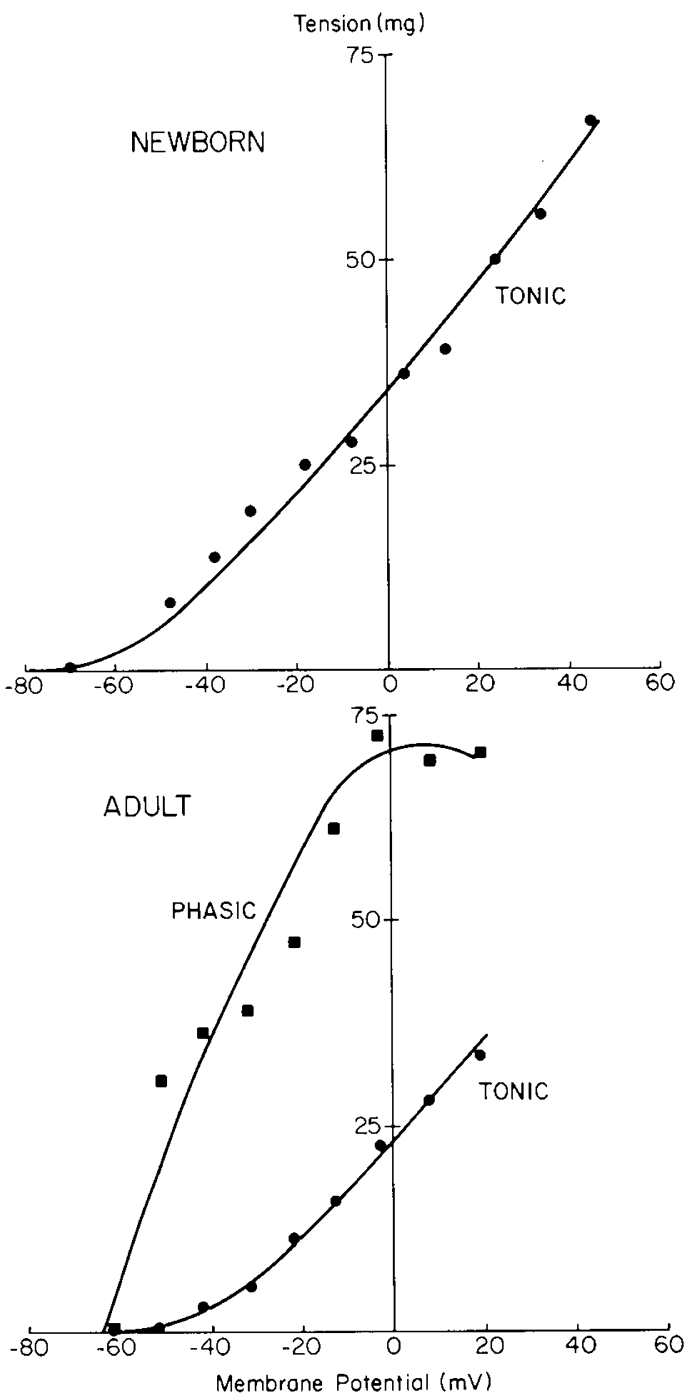

Fig. 5. The relationship between tension and voltage is plotted for 2-s voltage clamp steps in typical newborn (top) and adult (bottom) papillary muscles. Tension-voltage relations are generated by varying the clamp potential (plotted on the $X$ axis) and measuring the developed tension (plotted on the $Y$ axis). Tonic tension displays a similar voltage dependence in the newborn and adult. Only the adult displays measurable phasic tension. Note that the voltage dependence of phasic tension seen in the adult is different from that of tonic tension.

tension, seen only in the mature myocardium, was different from that of tonic tension.

Phasic tension and the sarcoplasmic reticulum. The results of this investigation are consistent with the hypothesis that the contribution of the sarcoplasmic reticulum to excitation-contraction coupling in mammalian myocardium increases with age. Previous investigations have indicated that the phasic component of voltage clamp controlled tension is generated by release of $\mathrm{Ca}^{2+}$ from the sarcoplasmic reticulum triggered by depolarization (2). Other mechanisms of generation of the phasic component of tension, however, must be considered. Most importantly, tension records such as those reported herein might be generated because voltage clamp control was not optimal at the beginning of long clamp steps. Escape action potentials within the physiologic segment of the papillary muscle might then cause the transient development of the twitch-like tension measured in this series of experiments. The measured increase in phasic tension with development, then, might reflect a decreased ability to achieve voltage clamp control in the more mature preparations. The $\mathrm{Ca}^{2+}$-loading experiments provide evidence against this possibility. In these experiments, two identical voltage clamp steps are imposed sequentially on the papillary muscle (Fig. 4). Whereas the first produces little or no phasic tension in the neonate, the second produces a more adult-like response. There is no a priori reason to suppose that the voltage control of the second clamp step is less good than that of the first. It is therefore unlikely that clamp control is adequate in the conditioning clamp step but inadequate in the test clamp step, allowing escape action potentials and twitch-like tension. A more likely explanation is that the sarcoplasmic reticulum which is present, but not functional to any significant extent, in the newborn myocardium, is loaded with $\mathrm{Ca}^{2+}$ by the conditioning clamp step and that the release of this $\mathrm{Ca}^{2+}$ load during the test clamp produces phasic tension not seen under control conditions. Consistent with this explanation, the phasic tension of the juvenile myocardium is also increased by $\mathrm{Ca}^{2+}$ loading (Table 1). These results are consistent with the notion that the sarcoplasmic reticulum is present but functionally immature in the newborn rabbit. Under conditions of $\mathrm{Ca}^{2+}$ loading, however, the immature sarcoplasmic reticulum may play a role in excitation-contraction coupling.

Mechanisms tension generation. Our experiments indicate that, in all age groups, tonic tension is under direct control of the membrane potential, similar to the tonic tension component of amphibian ventricle that is supported by the transport of $\mathrm{Ca}^{2+}$ into the cell from the extracellular space (16). If tonic tension in mammalian myocardium represents transsarcolemmal $\mathrm{Ca}^{2+}$ influx, then the similarity between the tension voltage relation for tonic tension in the neonate and adult (see Fig. 5) suggests that the voltage dependence of the mechanism by which $\mathrm{Ca}^{2+}$ is transported into the cell does not change with age.

The relative contributions of transsarcolemmal $\mathrm{Ca}^{2+}$ influx and the release of $\mathrm{Ca}^{2+}$ from the sarcoplasmic reticulum has been evaluated by measuring the ratio of phasic to tonic tension. The increase in this ratio in response to $\mathrm{Ca}^{2+}$ loading has already been discussed. The ratio, however, also has been demonstrated to increase with development (Fig. 3), consistent with a maturational increase in $\mathrm{Ca}^{2+}$ sequestration and rerelease by the sarcoplasmic reticulum. In the immature myocardium, it would appear that $\mathrm{Ca}^{2+}$ transport across the sarcolemma from the extracellular space is the primary mechanism responsible for tension generation. Several observations support this notion. Importantly, the immature myocardium displays only tonic or membrane potential controlled tension in response to voltage clamp steps (Fig. 2). Further, only in the neonate was the steady state component of tension generated by a voltage clamp step to the plateau potential of sufficient magnitude to account for the twitch tension accompanying an action potential. In addition, influx of $\mathrm{Ca}^{2+}$ from the extracellular space as a mechanism of tension generation is well suited to the neonatal myocyte. Its smaller size (10) allows $\mathrm{Ca}^{2+}$ transported across the membrane to easily reach the interior of the cell. The subsarcolemmal arrangement of myofilaments further reduces diffusion distances for $\mathrm{Ca}^{2+}$ crossing the membrane to reach the contractile and regulatory proteins. Finally, if mitochondrial energy production advances with progressive maturation, it should be recognized that either diffusion or coupled transport of $\mathrm{Ca}^{2+}$ from the extracellular space into the cell does not directly require ATP.

Our results are compatible with a developmental scheme (Fig. 6) for excitation-contraction coupling in which immature myocardium relies on membrane depolarization to directly control $\mathrm{Ca}^{2+}$ influx and deliver $\mathrm{Ca}^{2+}$ to the myofilaments to activate contraction. With development, as the ability to store and rere- 


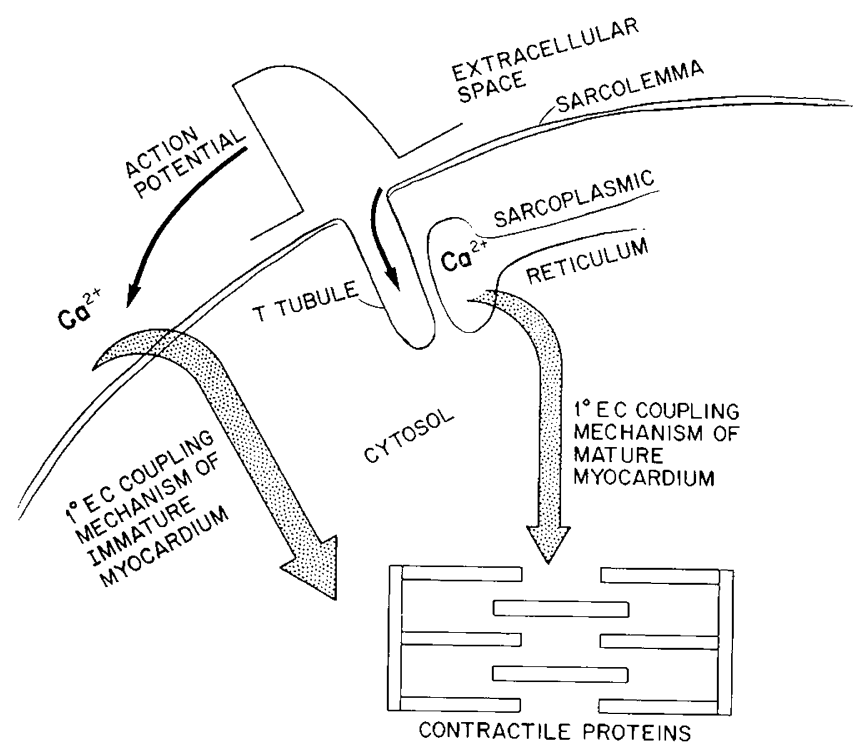

Fig. 6. A model of excitation-contraction coupling is schematically depicted. The action potential as it propagates through the myocardium causes membrane depolarization and modulates $\mathrm{Ca}^{2+}$ influx and delivery to the myofilaments. This mechanism is thought to be the primary mechanism of excitation-contraction coupling in the immature myocardium. With development, as the t-tubular system appears and the sarcoplasmic reticulum becomes functionally mature, action potential triggered release of $\mathrm{Ca}^{2+}$ from the sarcoplasmic reticulum plays an increasingly important role in excitation-contraction coupling.

lease intracellular $\mathrm{Ca}^{2+}$ increases, this second mechanism augments the rise in intracellular free $\mathrm{Ca}^{2+}$ which accompanies the action potential and results in tension generation. This scheme is consistent with the observations that immature myocardium does not possess the well developed t-tubular system and sarcoplasmic reticulum of the adult (7-11); that the sarcoplasmic reticulum of the immature myocardium is functionally less able to sequester and rerelease $\mathrm{Ca}^{2+}$ than that of the adult (17-19); that the newborn and fetal myocardium are less sensitive to changes in stimulation rate $(7,20)$; and that the dependence on the extracellular concentration of $\mathrm{Ca}^{2+}$ is greater for newborn myocardium than adult (4). This model, which is similar to previous proposals $(2,5-7,21)$, would explain the direct control of membrane potential over steady state tension and the absence of phasic tension seen in the newborn. Additionally, the increase in phasic tension seen with maturity may serve as a marker for the development of the functional role of the sarcoplasmic reticulum in excitation-contraction coupling.

\section{REFERENCES}

1. Chapman RA 1979 Excitation-contraction coupling in cardiac muscle. Prog Biophys Mol Biol 35:1-52

2. Morad M, Goldman Y 1973 Excitation-contraction coupling in heart muscle: membrane control of development of tension. Prog Biophys Mol Biol $27: 257-313$

3. Bassingthwaite JB, Reuter H 1972 Calcium movements and excitation-contraction coupling in cardiac cells. In: deMello WC (ed) Electrical Phenomena in the Heart. Academic Press, New York, pp 353-395

4. Jarmakani JM, Nakanishi T, George BL, Bers DM 1982 The effect of extracellular calcium on myocardial mechanical function in the neonatal rabbit. Dev Pharmacol Ther 5:1-13

5. Rashid N, Reedy MC, Anderson PAW 1987 Developmental changes in the ultrastructure and sarcomere shortening of the isolated rabbit ventricular myocyte. Circ Res 61:465-483.

6. Nakanishi T, Okuda H, Kamata K, Abe K, Sekiguchi M, Takao A 1987 Development of myocardial contractile system in the fetal rabbit. Pediatr Res 22:201-207.

7. Maylie JG 1982 Excitation-contraction coupling in neonatal and adult myocardium of cat. Am J Physiol 242:H834-H843

8. Legato M 1975 Ultrastructural changes during normal growth in the dog and cat ventricular myofibre. In: Lieberman M, Sano T (eds) Development and Physiologic Correlates of Cardiac Muscle. Raven Press, New York, pp 249274

9. Sheldon CA, Friedman WF, Sybers HD 1976 Scanning electron microscopy of fetal and neonatal lamb cardiac cells. $J$ Mol Cell Cardiol 8:853-862

10. Sheridan DJ, Cullen MJ, Tynan MJ 1979 Qualitative and quantitative observations on ultrastructuaral changes during postnatal development in cat myocardium. J Mol Cell Cardiol 11:1173-1181

11. Hoerter J, Mazet F, Vassort G 1981 Perinatal growth of the rabbit cardiac cell: possible implications for mechanism of relaxation. J Mol Cell Cardiol 13:725-740

12. Morad M, Orkand RK 1971 Excitation-contraction coupling in frog ventricle: evidence from voltage clamp studies. J Physiol 219:167-189

13. Goldman Y, Morad M 1977 Measurement of transmembrane potential and current in cardiac muscle: a new voltage clamp method. J Physiol 268:613654

14. Morad M, Trautwein W 1968 The effect of the duration of the action potential on contraction in the mammalian heart muscle. Pflugers Arch 299:66-82

15. Ochi R, Trautwein W 1971 The dependence of cardiac contraction on depolarization and the slow inward current. Pflugers Arch 323:187-203

16. Klitzner T, Morad M 1983 Excitation-contraction coupling in frog ventricle: possible $\mathrm{Ca}^{2+}$ transport mechanisms. Pflugers Arch 398:274-283

17. Nayler EG, Fassold E 1977 Calcium accumulating and ATPase activity of cardiac sarcoplasmic reticulum before and after birth. Cardiovasc Res 11:231-237

18. Mahoney L, Jones LR 1986 Developmental changes in cardiac sarcoplasmic reticulum in sheep. J Biol Chem 261:15257-15265

19. Fabiato A, Fabiato F 1978 Calcium-induced release of calcium from the sarcoplasmic reticulum of skinned cells from adult human, dog, cat, rabbit, rat. and frog hearts and from fetal and newborn rat ventricles. Ann NY Acad Sci 307:491-522

20. Kirkpatrick SE, Naliboff J, Pitlick PT, Friedman WF 1975 Influence of poststimulation potentiation and heart rate on the fetal lamb heart. Am J Physiol 229:318-323

21. George BL, Shimizu T, Jarmakani JM 1984 Caffeine effect on myocardial mechanical function in the neonatal rabbit heart. Dev Pharmacol Ther $7: 398 \sim 408$ 